\title{
Comparison between Dry, MQL, and Cryogenic Cooling Technique on Surface Integrity of Burnished Surface
}

\author{
Haris Rachmat ${ }^{1}$, Khairuddin Mahalil ${ }^{2}$, Zazuli Mohid ${ }^{3}$, Erween Abd Rahim ${ }^{3^{*}}$ \\ ${ }^{1}$ Fakultas Rekayasa Industri, Telkom University, Bandung, INDONESIA \\ ${ }^{2}$ Machinery Technology Centre, SIRIM Berhad, Hulu Selangor, MALAYSIA \\ ${ }^{3}$ Precision Machining Research Center, Universiti Tun Hussein Onn Malaysia, Batu Pahat, Johor, MALAYSIA \\ *Corresponding Author
}

DOI: https://doi.org/10.30880/ijie.2019.11.05.005

Received 8 January 2019; Accepted 17 April 2019; Available online 10 August 2019

\begin{abstract}
Environmental concerns has contributed towards higher demands for green products. Therefore, various machining conditions, such as dry and near dry machining have been introduced to resolve the cutting fluid problem. However, the application of cryogenic cooling still not well understood especially for burnishing process. It is essential to initiate a study on the effect of cryogenic cooling technique to substitute other techniques to improvement burnishing process. Carbon dioxide is used as the cryogenic gas under supercritical state, and compare with dry and minimal quantity lubricant. Solid carbide burnishing tool is used with a diameter and corner radius of $16 \mathrm{~mm}$ and $1 \mathrm{~mm}$, respectively. The result shows that burnishing process under cryogenic condition recorded less burn mark and better tool wear than dry and MQL conditions. In addition, cryogenic condition exhibits significant grain refinement and surface hardness. In conclusion, the performance of carbon dioxide gas under supercritical state outperformed other coolant conditions.
\end{abstract}

Keywords: Burnishing; Cryogenic coolant; Carbon dioxide, MQL

\section{Introduction}

Continuous improvement in manufacturing industries especially in machining processes are really needed and highly demands [1]. Efficiency in machining process versus high quality product, cost saving in manufacturing process, and an environmentally friendly. Sustainable manufacturing is a part of research studies for continuous improvement in manufacturing activities [2]. Comparison the performance of dry, MQL and cryogenic cooling techniques is most popular research works. Near-dry machining or minimum quantity lubrication (MQL) and cryogenic coolant have shown a good performance especially in terms of pro-long the cutting tool life and improve surface integrity. For dry burnishing, rising the temperature at the burnishing tool and workpiece contact point always gave the highest value [3].

One of advanced manufacturing method is burnishing process. The burnishing process can be classified into seven categories, namely ball burnishing, roller burnishing, eccentric ball burnishing, electrical discharge machining (EDM) with ball burnishing, laser assisted ball burnishing, low plasticity burnishing (LPB) and frictional stir burnishing (FSB) process. The researchers [4] have studied the mechanics of the ball burnishing process using 3D numerical models and affects the mechanics of the ball burnishing process is done in their research works. The findings, by numerical models of roller burnishing are based on the assumption of equivalence between burnishing and normal indentation contact are too weak to provide a solid estimation of the geometrical and mechanical characteristics of a roller-burnished surface. [5-6] successfully studied the effects of burnishing tool size and coolant techniques on burnishing performance. Roller 
burnishing proved to be a more appropriate finishing process, improves the surface finish and increases the micro hardness. With a few parameters such as burnishing force, speed, feed, roller width, and number of pass. [7] studied on the effect of cryogenic burnishing and compare it with dry and MQL conditions. They found that cryogenic cooling recorded the lowest burnishing force and temperature when compared to dry and MQL conditions. The surface quality was improved significantly under cryogenic burnishing.

[8] investigates on the effect of number of burnishing passes on the integrity of the burnished surface. They summarized that the damage on the burnished surface is significant when multiple passes of burnishing process were applied. Multiple passes cause over hardening on the burnished surface, consequently flaking of the surface layers. Laser-assisted burnishing (LAB) was studied by [9] and it was compared with conventional burnishing in terms of surface finish, surface hardness and residual stress. It is shown that LAB exhibits excellent surface finish, higher surface hardness and similar compressive residual stress compared to its conventional burnishing.

[10] studies on the effects of sequential turning and burnishing process on surface integrity of $\mathrm{Cr}-\mathrm{Ni}$-based stainless steel. It was found that surface integrity such as surface roughness, microhardness and residual stress are improved when the sequential turning and burnishing process is employed. [11] focus on to development of frictional stir burnishing and study its effect on $0.45 \% \mathrm{C}$ steel. They reported that smaller tool tip radius produces thinner hardened layer but the surface roughness value becomes worst.

Burnishing is a cleaner process and capable to eliminate slower and costlier finishing processes and secondary operations such as grinding, honing or lapping [12]. It is the post machining activities that improves dimensional accuracy, surface hardness and residual stresses [13]. Generally, burnishing process is operated under dry condition without using any lubricant. However, it impairs the quality of the burnished surface [14]. This issue can be solved by applying near-dry coolant or cryogenic burnishing. Under near-dry condition, the lubricant was sprayed with very minimum quantities and it was formed as a mist [15-16]. The most essential criteria to select cryogenic gases are clean, safe and environmentally friendly [17]. Cryogenic burnishing uses liquid nitrogen as a coolant but this gas is tough to handle and maintain. Recently, carbon dioxide gas has been introduced in the pipe line to replace liquid nitrogen $[18,19,20]$. In this study, various coolant condition such as dry, MQL, and cryogenic cooling techniques are compared in term of workpiece surface integrity and burnishing tool wear.

Table 1 - Burnishing parameters

\begin{tabular}{l|l}
\hline \multicolumn{1}{c|}{ Parameters } & \multicolumn{1}{c}{ Value(s) } \\
\hline Spindle speed, (rpm) & 10,000 \\
Indentation force $(\mathrm{N})$ & 750 \\
Number of tool passes & 1 \\
Feed rate (mm/min) & 200 \\
Burnishing tool material & Carbide (Grade K10) \\
Burnishing tool diameter (mm) & 16 \\
Corner radius of tool (mm) & 1 \\
Cooling Techniques & Dry, MQL, $\mathrm{SCCO}_{2}+\mathrm{MQL}$ \\
Workpiece material & Carbon steel $\left(\mathrm{SS}_{000}\right)$ \\
\hline
\end{tabular}

\section{Experimental Setup}

In this experiment, carbon steel (SS400) was used as a workpiece material for Frictional Stir Burnishing (FSB) process. The configuration of FSB tool is shown in Fig. 1. CNC vertical machining center (MAZAK Nexus 410A) was used to perform the burnishing experiment. The testing material was mounted on the piezoelectric force sensor dynamometer (Kistler Dynamometer 9254) as shown in Figure 2. The multichannel amplifier 5070A is transferred and translate the signals from the dynamometer. A cylindrical tungsten carbide grade K10 with diameter and corner radius of $16 \mathrm{~mm}$ and $1 \mathrm{~mm}$, respectively was used as a burnishing tool. It was inserted into the tool holder at the constant overhang of $20 \mathrm{~mm}$. There is a spring with a stiffness of $157 \mathrm{~N} / \mathrm{m}$, installed inside the tool holder for a purpose to control the burnishing tool preload. The burnishing tool is rotating and moves linearly on the workpiece surface. The experimental setup for FSB process and parameters is shown in Fig. 2 and Table 1, respectively. The parameters for both MQL and $\mathrm{SCCO}_{2}+\mathrm{MQL}$ is shown in Table 2. The carbon dioxide gas was compressed until it reaches to supercritical state.

The tool maker microscope as shown in Fig. 3 was used to capture and analyses the worn burnishing tools. This equipment outfitted with a camera and software which capable to capture the image of the tools under high magnification. Lens with high magnifying of 10- and 30-times magnification were used to capture the image of burnishing tool wear. Vickers hardness tester was used to measure the value of micro-hardness of workpiece as shown in Fig. 4. The indentation force and the time interval were set at $0.2 \mathrm{kgf}$ and 10 seconds, respectively. The diamond shape that form from the indenter then measured and converted to a hardness value by using HVM software. The 
workpiece samples were prepared to identify and analyze the heat affected zone (HAZ) region along the burnished surface. HAZ was determined by observing the changes of microstructure as shown in Fig. 5. The samples were mounted as a cold mounting using EpoxiCure 2 epoxy resin and hardener with the sample was placed on the top surface.

Table 2 - Coolant parameters

\begin{tabular}{l|l|c}
\hline Cooling technique & \multicolumn{1}{|c}{ Parameters } & Values \\
\hline \multirow{3}{*}{$\mathrm{MQL}$} & Input pressure $(\mathrm{MPa})$ & 0.4 \\
& Nozzle distance $(\mathrm{mm})$ & 8 \\
& Nozzle angle $\left(^{(}\right)$ & 45 \\
& Lubricant type & Synthetic Ester \\
& Lubricant flow rate $(1 / \mathrm{hr})$ & 0.16 \\
\hline & Input pressure $(\mathrm{MPa})$ & 10.4 \\
$\mathrm{SCCO}_{2}+\mathrm{MQL}$ & Nozzle distance $(\mathrm{mm})$ & 8 \\
& Nozzle angle $\left(^{(}\right)$ & 45 \\
& Lubricant type & Synthetic Ester \\
& Lubricant flow rate $(1 / \mathrm{hr})$ & 2.61 \\
\hline
\end{tabular}

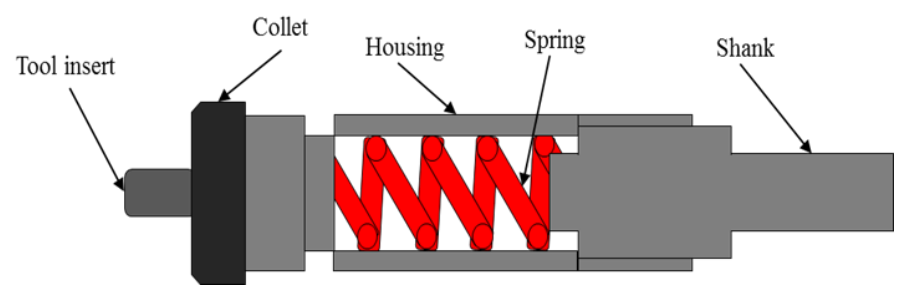

Fig. 1 - Frictional Stir Burnishing (FSB)

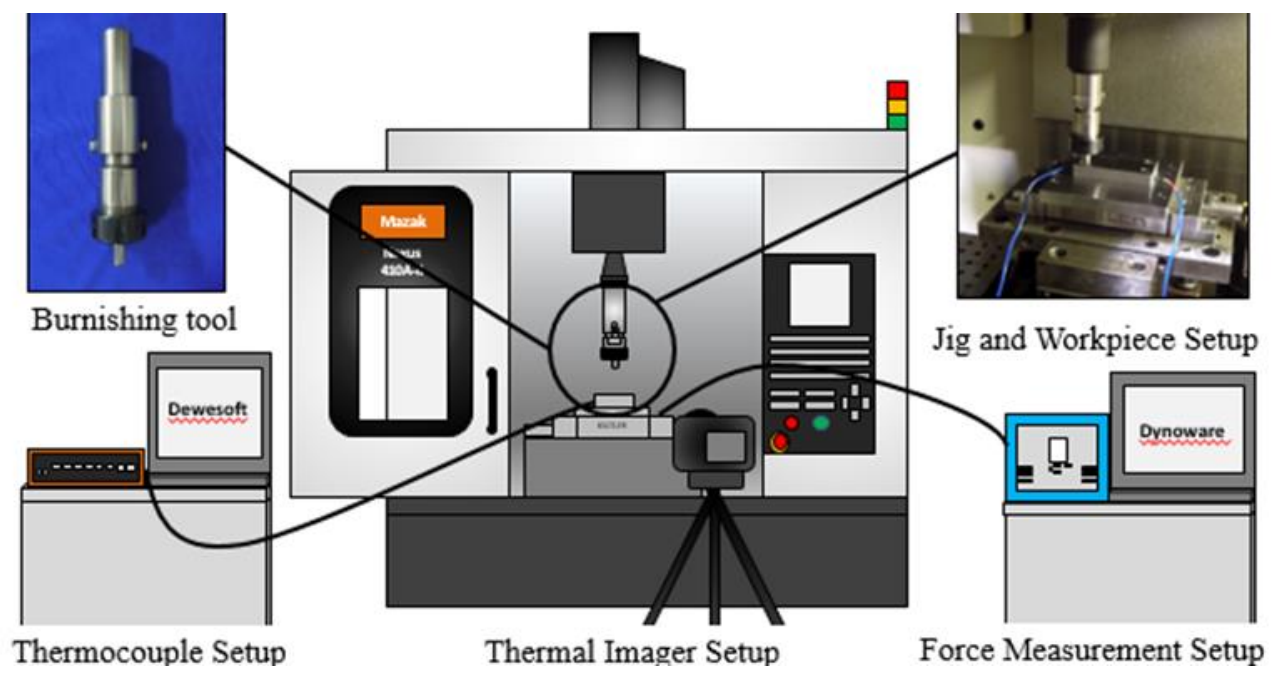

Fig. 2 - Experimental set up for burnishing process 

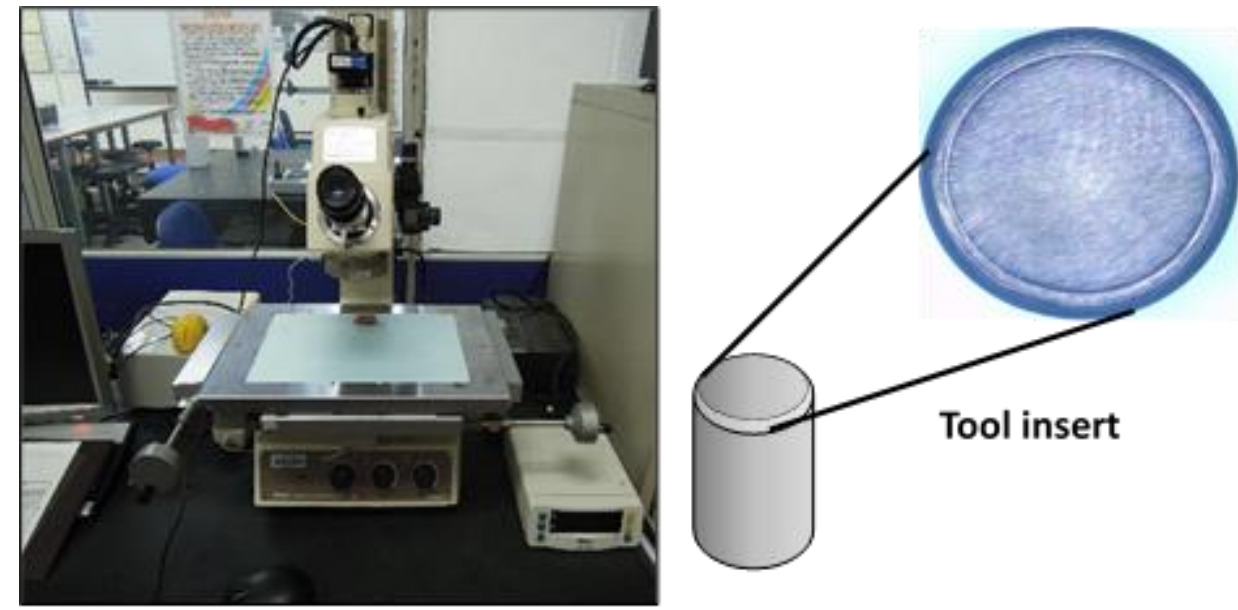

Fig. 3 - Set up for analysis tool wear

\section{Vickers Hardness Tester}

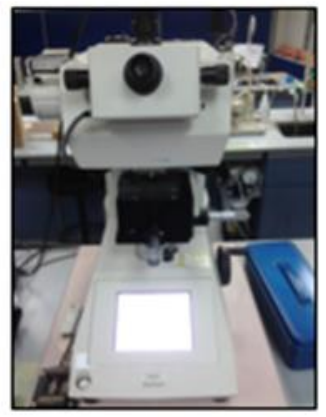

Force: $\mathbf{0 . 2} \mathbf{k g f}$ Indentation time: $10 \mathrm{~s}$

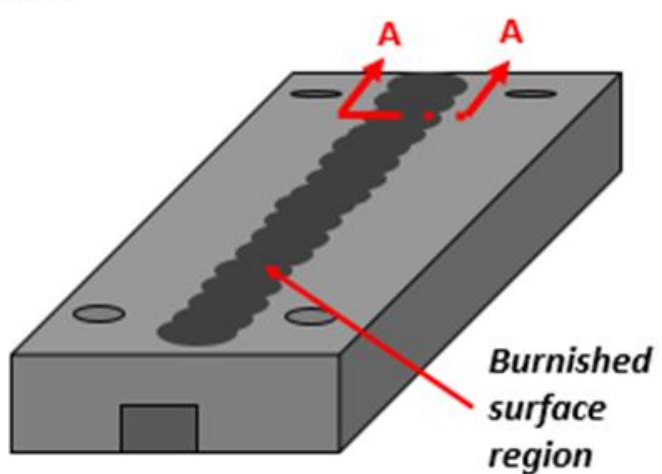

region

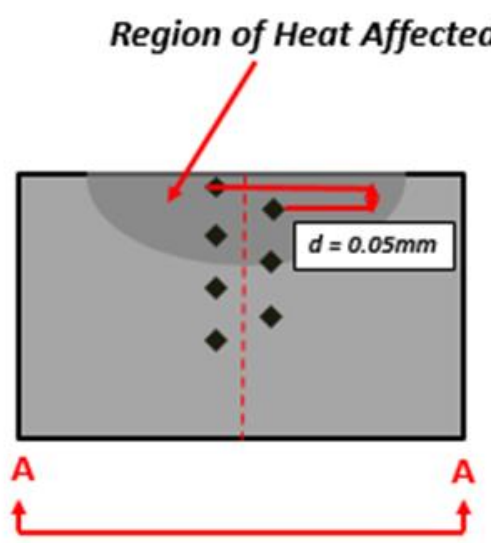

Fig. 4 - Set up for measurement of microhardness
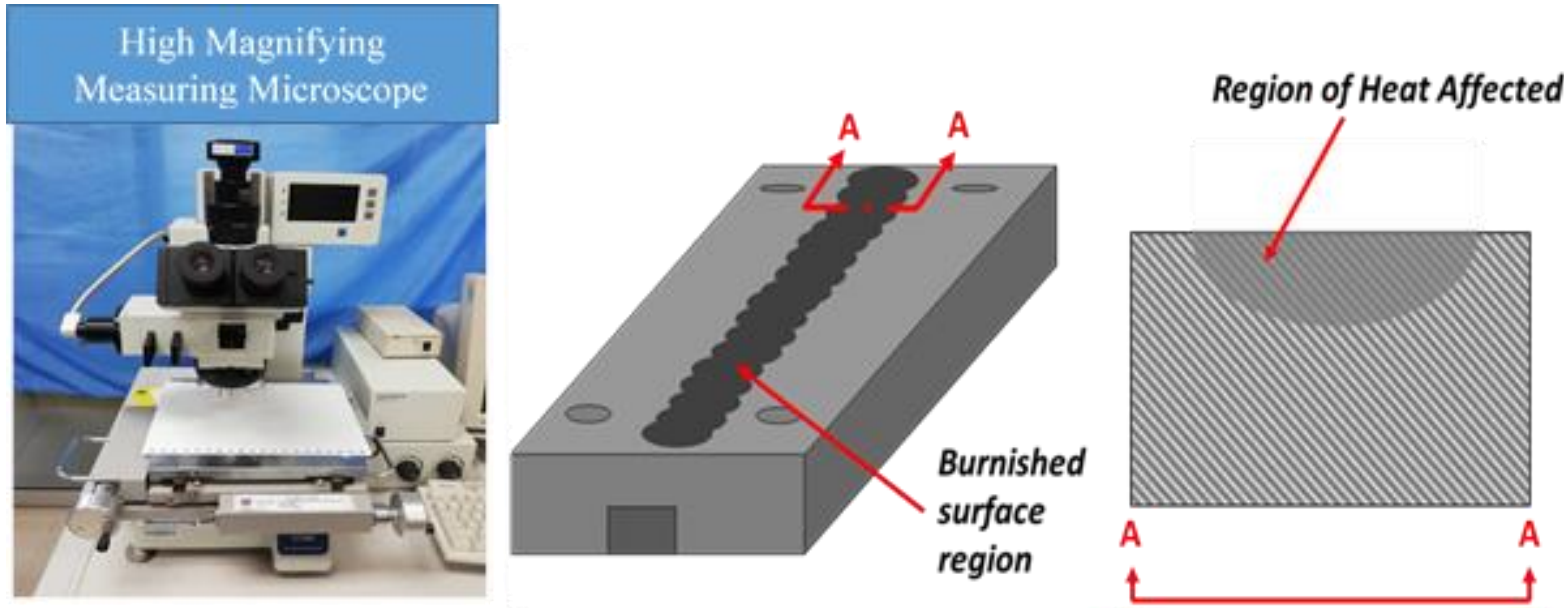

Fig. 5 - Set up for changes of microstructure

\section{Results and Discussion}

\subsection{Tool Wear}

Fig. 6 shows the photograph of tool surface after undergone burnishing process at $100 \mathrm{~mm}$ in length. The process takes approximately 50 seconds to finish at a constant spindle speed and feed rate. The formation of burnishing tool wear was captured using tool maker microscope at a magnification of 10 and 30 times. The contact area is differing according to the cooling technique. 
Tool wear progression such as chipping, tool breakage, tool worn and burn marked can be seen on the tool surface. This is due to the generation of high temperature and friction during the burnishing process. These wear characteristics occurred due to the sliding contact between tool and workpiece interface during burnishing process [11,19]. This is due to the depth of indentation depending on the tool diameter. In addition, the depth of indentation could affect the burnishing process. The depth of indentation increases when using smaller burnishing tool diameter. Smaller diameter reduces the tool contact area on the workpiece surface, thus high friction was produced and caused the tool wear.

The progression of tool wear under dry condition shows more aggressive compared with MQL and cryogenic condition. However, MQL gives a significant to reduce the tool wear progression. The existence of mist lubricant from the MQL reduces the cutting force and heat generated from the burnishing and other machining processes [24, 26]. Therefore, it decelerates the tool wear progression compared to dry condition. The lowest tool wear progression was obtained when applying $\mathrm{SCCO}_{2}+\mathrm{MQL}$. At the highest of cooling rate and lubricant flow rate, this condition effectively helped in reduced the heat generation and the burnishing force during the burnishing process. As stated by [18], the higher quantity of lubricant from the $\mathrm{SCCO}_{2}+\mathrm{MQL}$ condition helps to reduce the friction and decreasing the cutting temperature, subsequently lowering the progression of tool wear as well as extending the tool life.

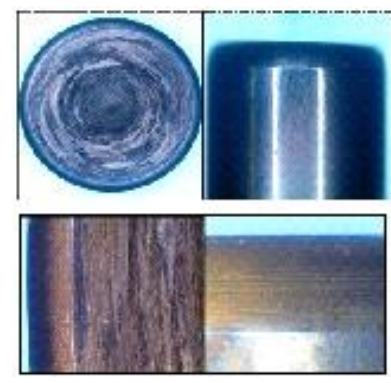

Dry

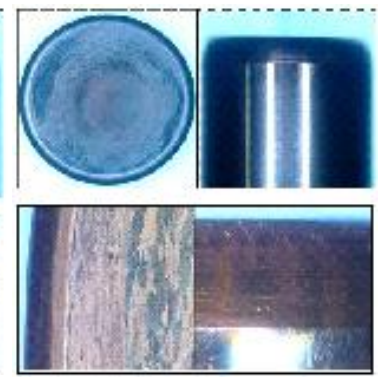

MQL

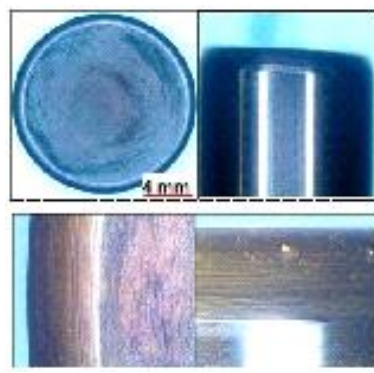

$\mathrm{SCCO}_{2}+\mathrm{MQL}$

Fig. 6 - Result for tool diameter $16.00 \mathrm{~mm}$, corner radius $1.0 \mathrm{~mm}$

\subsection{Microhardness}

Fig. 7 shows the results of the tool diameter of $16 \mathrm{~mm}$ respectively. It was observed that by applying $\mathrm{SCCO}_{2}+$ MQL, the value of microhardness was significantly increased by $7.4 \%$ and $46 \%$ when compared to MQL and dry conditions, respectively. Under dry condition, the phenomena of thermal softening are more dominant than strain hardening [21]. This is due to the accumulation of heat at the burnishing region, so that the annealing process was took place. Therefore, softer surface was obtained when compared with other cooling techniques. Both $\mathrm{SCCO}_{2}+\mathrm{MQL}$ and MQL have a tendency to increase the value of microhardness, accelerating the removal of heat, so that more strain hardening occurred underneath the burnished surface.

It shows that, $\mathrm{SCCO}_{2}+\mathrm{MQL}$ significantly improves the surface hardness when compared to dry and MQL conditions. At this condition, the higher value of microhardness underneath the burnished surface was produced. Meanwhile, under dry condition, the higher value of hardness only on the surface. Cryogenic gas produces a temperature approximately $-70^{\circ} \mathrm{C}$. Therefore, it is capable to removes more heat during the burnishing operation, hence allows the microstructure of material to be compressed at higher burnishing force [21,25]. It is also acting as a quenching process during the burnishing process. Thus, the effect of strain hardening is more dominant than thermal softening. By applying cryogenic cooling techniques, it caused the effect of cryogenic treatment on the burnished surface by rapid cooling, hence increases the surface hardness. Therefore, by applying $\mathrm{SCCO}_{2}+\mathrm{MQL}$ drastically improves the microhardness of the workpiece.

\subsection{Microstructure}

Fig. 8 shows the result, it was observed under dry condition, burnishing tool with the diameter of 16 mm shows a formation of featureless layer with a darker appearance in which the grain boundaries were no longer visible. The thickness of this deformed layer is approximately $21 \mu \mathrm{m}$ underneath the burnished surface. Severe shear deformation was occurred underneath the burnished surface, whereby the grains tend to elongate and then it disappeared near the surface. Therefore, the microstructures were modified and the region becomes thicker.

MQL condition exhibits a significant reduction of dark layer region when compared to the dry condition. This is due to the lubricant supply to the burnishing zone which helps to reduce the burnishing force and temperature. During burnishing process, high friction was produced and more heat was accumulated on the burnishing zone.

However, by applying $\mathrm{SCCO}_{2}+\mathrm{MQL}$ as a cooling technique with a high cooling rate lubricant flow rate, rapid cooling was taken place and it easier to dissipates the heat and reduces the friction at the burnishing zone. Hence, the thickness of the darker appearance is less severe. It is similar to the machined surfaces of AISI 52100 steel conducted by [22] and nickel-based alloy IN-100 conducted [23], under cryogenic cooling technique. They found that by applying 
cryogenic cooling technique, the featureless layer becomes white and the darker appearance is not clearly visible, where significant grain refinement to the nanocrystalline level was found due to dynamic recrystallization (DRX).

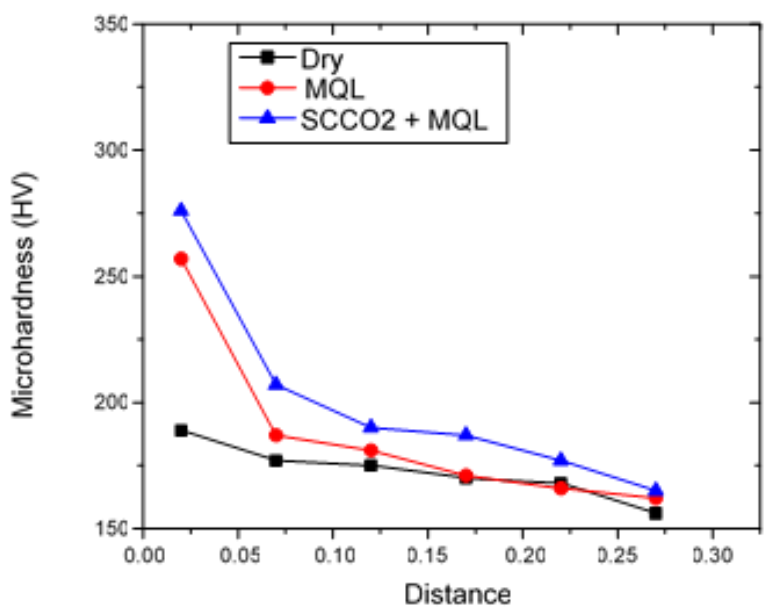

Fig. 7 - Microhardness result for $\mathrm{SCCO}_{2}+\mathrm{MQL}, \mathrm{MQL}$ and dry conditions

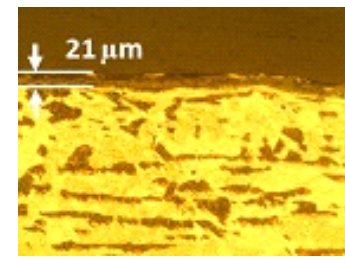

Dry

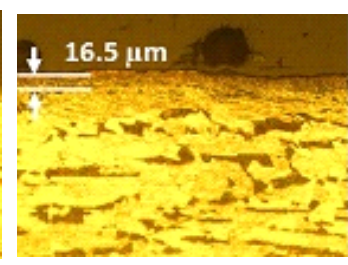

MQL

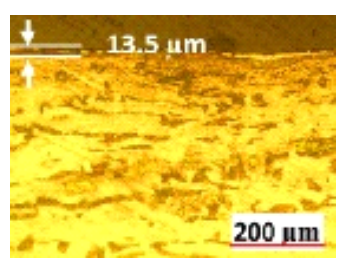

$\mathrm{SCCO} 2+\mathrm{MQL}$

Fig. 8 - Result for microstructure

\section{Conclusion}

This research works is to evaluate the burnishing performance by comparing between dry, MQL, and cryogenic cooling technique $\left(\mathrm{SCCO}_{2}+\mathrm{MQL}\right)$ in terms of tool wear, microhardness and heat affected zone (HAZ). The major conclusions and the results can be summarized as follows:

i. By visual, tool wear under dry condition shows more aggressive (rough surface) when compared with MQL and $\mathrm{SCCO}_{2}+\mathrm{MQL}$. Under MQL condition, it shows a significant reduction tool wear progression. However, the lowest tool wear progression was obtained when applying $\mathrm{SCCO}_{2}+\mathrm{MQL}$.

ii. It was observed that by applying $\mathrm{SCCO}_{2}+\mathrm{MQL}$, the value of the microhardness value was significantly increased by $7.4 \%$ and $46 \%$ when compared to MQL and dry conditions. Under dry condition, thermal softening is more dominant than strain hardening.

iii. Dry condition shows a formation of featureless layer with a darker appearance in which the grain boundaries were no longer visible. MQL condition exhibits a significant reduction of dark layer thickness when compared to dry condition. $\mathrm{SCCO}_{2}+\mathrm{MQL}$ possess high cooling rate and lubricant flow rate, whereby rapid cooling was taken placed. It is easier to removes the heat and reduces the friction at the burnishing zone.

\section{Acknowledgement}

The authors would like to thank Universiti Tun Hussein Onn Malaysia for the financial support of the Fundamental Research Grant Scheme 1594.

\section{References}

[1] Grzesik, W. and Zak, K. (2012). Modification of surface finish produced by hard turning using superfinishing and burnishing operations. Journal of Material Processing Technology, 212, 315-322.

[2] Rahim, E. A., Ibrahim, M. R., Rahim, A. A., Aziz, S. and Mohid, Z. (2015). Experimental investigation of minimum quantity lubrication (MQL) as a sustainable cooling technique. Procedia CIRP, 26, 351-354.

[3] Low, K. O. and Wong, K. J. (2011). Influence of ball burnishing on surface quality and tribological characteristics of polymers under dry sliding conditions. Tribology International, 44 (2), 144-153. 
[4] Balland, P., Tabourot, L., Degre, F. and Moreau V. (2013). Mechanics of the burnishing process. Precision Engineering, 37 (1), 129-134.

[5] Rachmat, H., Rahim, E. A., Mohid, Z., Mahalil, K., Kasah, A. A. K. F. and Nadzri, A. (2019). Effect of burnishing tool diameter and coolant strategies on burnishing performance. IOP Conference Series: Journal of Physics: 1150, 012070.

[6] Rachmat, H., Rahim, E. A., Mohid, Z., Mahalil, K., Kasah, A. A. K. F. and Nadzri, A. (2019). Effect of burnishing tool radius and coolant technique on burnishing performance. IOP Conference Series: Journal of Physics: 1150, 012047.

[7] Mahalil, K., Rahim, E. A. and Mohid, Z. (2019). Performance evaluation of sustainable coolant techniques on burnishing process," IOP Conference Series: Materials Science and Engineering, 494, 012001.

[8] El-Khabeery M. M. and El-Axir, M. H. (2001). Experimental technique for studying the effects of milling rollerburnishing parameters on surface integrity. International Journal of Machine Tools and Manufacture, 41 (12), 1705-1719.

[9] Tian, Y. and Shin, Y. C. (2007). Laser-assisted burnishing of metals. International Journal of Machine Tools and Manufacture, 47(1), 14-22.

[10] Zhang, P. and Liu, Z. (2015). Effect of sequential turning and burnishing on the surface integrity of Cr-Ni-based stainless steel formed by laser cladding process. Surface Coatings Technology, 276, 327-335.

[11] Takada, Y. and Sasahara, H. (2018). Effect of tip shape of frictional stir burnishing tool on processed layer's hardness, residual stress and surface roughness. Coatings, 8(32), 1-13.

[12] Hassan, A. M. and Maqableh, A. M. (2000). The effects of initial burnishing parameters on non-ferrous components. Journal Material Processing Technology, 102, 115-121.

[13] Huang, B., Kaynak, Y., Sun, Y. and Jawahir, I. S. (2015). Surface layer modification by cryogenic burnishing of Al 7050-T7451 alloy and validation with FEM-based burnishing model. Procedia CIRP, 31, 1-6.

[14] Mahajan, D. and Tajane, R. (2013). A review on ball burnishing process. International Journal of Scientific Research and Publication, 3(4), 1-8.

[15] Rahim, E. A. and Sasahara, H. (2009). Application of minimum quantity lubrication when drilling nickel-based superalloy at high cutting speed. Key Engineering Materials, 407-408, 612- 615.

[16] Rahim, E. A. and Sasahara, H. (2010). High speed MQL drilling of titanium alloy using synthetic ester and palm oil. 36th International MATADOR Conference, pp. 193- 196.

[17] Supekar, S. D., Clarens, A. F., Stephenson, D. A. and Skerlos, S. J. (2012). Performance of supercritical carbon dioxide sprays as coolants and lubricants in representative metalworking operations. Journal Material Processing Technology, 212(12), 2652-2658.

[18] Rahim, E. A., Rahim, A. A., Ibrahim, M. R., Mohid, Z. (2016). Experimental investigation of supercritical carbon dioxide cooling $\left(\mathrm{SCCO}_{2}\right)$ performance as a sustainable cooling technique. Procedia CIRP, 40, 637-641.

[19] Mulyana, T., Rahim, E. A. and Md Yahaya, S. N. (2017). The influence of cryogenic supercritical carbon dioxide cooling on tool wear during machining high thermal conductivity steel. Journal Cleaning Production. 164, 950962.

[20] Rahim, E. A., Jaafar, M. N., Mohid, Z., Ibrahim, M. R., and Ahmad, S. (2018). A study on cryogenic supercritical carbon dioxide coolant delivery technique when machining of AISI 1045 steel. Journal of Mechanical Engineering, 5(3), 37-49.

[21] Caudill, J., Huang, B., Arvin, C., Schoop, J., Meyer, K. and Jawahir, I. S. (2014). Enhancing the surface integrity of Ti-6Al-4V alloy through cryogenic burnishing. Procedia CIRP, 13, 243-248.

[22] Rao, D. S., Hebbar, H. S., Komaraiah, M. and Kempaiah, U. N. (2008). Investigations on the effect of ball burnishing parameters on surface hardness and wear resistance of HSLA dual-phase steels. Materials and Manufacturing Processes, 23(3), 295-302.

[23] Sun, S., Brandt, M. and Dargusch, M. S. (2017). Effect of tool wear on chip formation during dry machining of Ti-6Al-4V alloy, Part 1: Effect of gradual tool wear evolution. Proceedings of Institute of Mechanical Engineer Part B, Journal of Engineering Manufacture, 231(9), 1559-1574.

[24] Talib, N., Nasir, R. M. and Rahim, E. A. (2018). Investigation on the tribological behaviour of modified jatropha oil with hexagonal boron nitride particles as a metalworking fluid for machining process. International Journal of Integrated Engineering, 10 (3), 57-62.

[25] Thamizhmanii, S. and Hassan, S. (2009). An experimental work on multi-roller burnishing process on difficult to cut material - titanium alloy. International Journal of Integrated Engineering, 1 (1), 1-6.

[26] Sapian N. F., Omar, B. and Shukor, M. H. A. (2010). Integrated mechanical pulse jet coolant delivery system performance for minimal quantity lubrication. International Journal of Integrated Engineering, 2 (1), 53-68. 